Eur J Clin Chem Clin Biochem

$1995 ; 33: 329-335$

(c) 1995 Walter de Gruyter \& Co. Berlin - New York

\title{
Cyclic AMP-Related and Cation-Affected Human Platelet Chloride Transport Regulation
}

\author{
By Galila Agam ${ }^{1}$, Micha Aviram², Michaela Zilberman-Kaufman, Aser Rothstein ${ }^{3}$ and Avinoam A. Livne ${ }^{4}$
}

1 Unit of Clinical Biochemistry, Faculty of Health Sciences, Ben-Gurion University of the Negev, Beer Sheva, Israel

2 Unit of Pediatrics, Faculty of Health Sciences, Ben-Gurion University of the Negev, Beer Sheva, Israel

${ }^{3}$ Hospital for Sick Children, Toronto, Ontario, Canada

${ }^{4}$ Department of Life Sciences (deceased), Faculty of Natural Sciences, Ben-Gurion University of the Negev, Beer Sheva, Israel

(Received November 23, 1994/March 27, 1995)

Summary: Cystic fibrosis has been characterized as a defect in the regulation of cyclic AMP-dependent transepithelial chloride transport. The activation of cyclic AMP-dependent protein kinase A by cyclic AMP occurs normally in cystic fibrosis cells, but they fail to transport chloride ions in response to protein kinase A stimulation. Defective chloride secretion and abnormal electrolyte transport occurs in several organs including the lung, sweat glands, intestine and pancreas. The present work was aimed at exploring whether the same or similar regulatory systems are functional in platelets, and if they are altered or deficient in individuals with cystic fibrosis. Chloride transport in platelets from normal subjects and from cystic fibrosis patients was measured by cell sizing techniques where chloride permeability is the limiting factor. In platelets from healthy volunteers, the chloride channel blocker, 5-nitro-2-(3-phenylpropylamino) benzoic acid, inhibits the transport in a dose-dependent manner. The preservation of chloride transport capability is shown to be dependent upon the presence of either $\mathrm{Ca}^{2+}$ or two divalent cation substitutes, $\mathrm{Cd}^{2+}$ or $\mathrm{Cu}^{2+}$. It is also shown that in normal subjects $0.1 \mu \mathrm{mol} / 1$ prostaglandin $\mathrm{E}_{1}$, which elevates cyclic AMP 6 times and abolishes platelet aggregation, significantly enhances the rate constant of the transport. Furthermore, in five out of nine cystic fibrosis patients studied, platelet chloride transport did not respond to stimulation by prostaglandin $\mathrm{E}_{1}$.

\section{Introduction}

Chloride transport in various cells is a topic of great interest. In platelets, it has been studied in the context of their volume-regulatory behaviour (1). When subjected to hypotonic $\mathrm{NaCl}$ medium ( $200 \mathrm{mosmol} / \mathrm{l}$ ) platelets respond with a rapid swelling phase of 30 seconds followed by a volume decrease with a partial return toward the original volume (1). The reduction in volume in the second phase involves a loss of anions and potassium ions. The addition of the ionophore gramicidin to the medium induces a high permeability to both $\mathrm{Na}^{+}$ and $\mathrm{K}^{+}$, thus losses or gains of salts and the associated changes in volume are limited by the conductive anion permeability and provide its measurement (2). It has been shown (1) that platelets suspended in hypotonic
$\mathrm{NaCl}$ medium in the presence of gramicidin react with continuing swelling. In hypotonic $\mathrm{Na}_{2} \mathrm{SO}_{4}$ medium, on the other hand, the initial swelling (osmotic equilibration - attributed to the inflow of water driven by the imposed osmotic gradient) is followed by a modest shrinkage. It was assumed that the platelet membrane is impermeable to $\mathrm{SO}_{4}^{2-}$, with shrinkage driven by the outward chloride gradient. When $\mathrm{Na}^{+}$is replaced by $\mathrm{K}^{+}$(or $\mathrm{Rb}^{+}$) the volume decrease is abolished and the rapid initial swelling phase is followed by a slower secondary swelling (1). As expected, no secondary swelling was observed if $\mathrm{Na}^{+}$was replaced by the impermeate cation $\mathrm{N}$-methylglucamine. The rate of the secondary swelling in $\mathrm{KCl}$ medium is substantially enhanced by the addition 
of gramicidin, suggesting that in swollen platelets potassium permeability is the limiting factor of the rate of swelling. When this limiting factor is removed by gramicidin, the swelling becomes limited by chloride permeability. The permeabilities of two additional anions $\mathrm{SCN}^{-}$and $\mathrm{NO}_{3}^{-}$- behave like that of chloride, allowing a rapid secondary swelling at comparative rates, while citrate behaves like $\mathrm{SO}_{4}^{2-}$. The present work extends the studies to the effect of divalent cations on the platelet chloride permeability.

Cystic fibrosis is the most common congenital disease among Caucasians. It is a disease of the secretory epithelia, tissues that mediate the transport of chloride, accompanied by sodium and water, between the blood and the lumen. The secretion requires activation of the secretory pathway by hormones or neurotransmitters, utilizing cyclic AMP or $\mathrm{Ca}^{2+}$.

In recent years (1990-1992), the search for the basic defect in cystic fibrosis has reached a decisive stage since the identification of the responsible gene (3). It has been suggested that the $10 \mathrm{pS}$ gene product entitled cystic fibrosis transmembrane conductance regulator is either a regulator protein directing a chloride channel to the plasma membrane and conferring on it the ability to be regulated by cyclic AMP (4), or that it is a regulated chloride channel per se (5-7). Furthermore, the cystic fibrosis transmembrane conductance regulator has been purified to homogeneity and reconstituted into proteoliposomes in which it exhibited regulated chloride channel activity, providing evidence that the protein itself is the channel (8).

Platelet conductive ion fluxes exhibit similar features to those of epithelial cells (1), and are known to be responsive to hormones such as epinephrine, which is important in the regulation of fluid transport in the trachea and in sweat glands. Thus, the aim of the present work was to study chloride transport regulation in blood platelets, and to probe whether it is under cyclic AMP control.

\section{Materials and Methods}

Reagents and solutions

Gramicidin D, EGTA and prostaglandin $E_{1}$ were obtained from Sigma Chemical Co. (St. Louis, MO); 5-nitro-2-(3-phenylpropylamino) benzoic acid was a gift from Dr. B. Brauer from the Hebrew University of Jerusalem.

Acid-citrate-dextrose solution was composed of $65 \mathrm{mmol} / \mathrm{l}$ citric acid, $11 \mathrm{mmol} / 1$ glucose, and $85 \mathrm{mmol} / \mathrm{l}$ trisodium citrate. The Tyrode medium (modified), contained $137 \mathrm{mmol} / 1 \mathrm{NaCl}, 1 \mathrm{mmol} / 1$ $\mathrm{KCl}, 0.42 \mathrm{mmol} / \mathrm{l} \mathrm{Na} \mathrm{HPO}_{4}, 0.5 \mathrm{mmol} / 1 \mathrm{MgCl}_{2}, 5.5 \mathrm{mmol} / \mathrm{l} \mathrm{glu}-$ cose and $20 \mathrm{mmol} / \mathrm{l}$ HEPES, $\mathrm{pH} 7.35$, adjusted to $290 \mathrm{mosmol} / 1$. Stock solution of gramicidin $\mathrm{D}(1 \mathrm{mmol} / \mathrm{l})$ was prepared in dimethylsulphoxide.

\section{Subjects}

Assays in control platelets were performed with blood samples drawn randomly several times from ten healthy volunteers. Cystic fibrosis patients were from the Pediatric Cystic Fibrosis Clinic of the Soroka Medical Center, Ben-Gurion University Hospital in Beer Sheva. For all the children the diagnosis of cystic fibrosis was based on a sweat chloride concentration over $60 \mathrm{mmol} / \mathrm{l}$ and the presence of either pancreatic insufficiency or chronic obstructive pulmonary disease, or both. All the patients were under routine standard therapy including daily chest physiotherapy (by parents), high caloric diet with pancreatic enzymes and inhaled bronchodilators ( $\beta_{2}$-agonists). Antibiotics were given according to sputum culture results (only when exacerbation of respiratory symptoms occurred). However, all children were without any acute symptoms during the time of the study. All patients and/or their parents were fully aware of the tests, so that the blood samples were taken only after informed consent was obtained.

\section{Mutations analysis}

The mutations were studied by Dr. Bat-Sheva Kerem and coworkers from the Hadassah Medical School, Hebrew University, Jerusalem, as previously described (9).

\section{Preparation of platelet suspension}

Venous blood was obtained from subjects who had not taken any medication during the preceding 10 days. The blood was collected in plastic tubes and anticoagulated with acid-citrate-dextrose at a volume ratio of blood : anticoagulant of $6: 1$. Platelet-rich plasma was obtained by centrifugation at $120 \mathrm{~g}$ for $10 \mathrm{~min}$ and had a $\mathrm{pH}$ of $6.5 \pm 0.1$

Gel-filtered platelets were obtained by passing $0.5-0.8 \mathrm{ml}$ of platelet-rich plasma through a Sepharose $2 \mathrm{~B}$ column $(5.5 \times 0.76$ $\mathrm{cm}$ ), equilibrated with modified Tyrode medium. The platelets were eluted with the same medium.

Platelet volume and chloride permeability measurements

Volume measurements were conducted by electronic sizing using a Coulter counter, model ZF with a Coulter channelyzer $\mathrm{C} 1000$. Orifice diameter was $70 \mu \mathrm{m}$. An aliquot of the platelet suspension was diluted to a platelet count of $120 \cdot 10^{6} / 1$. The mean cell volume was calculated from the volume distribution curves using polystyrene latex beads for calibration. To determine the conductive anion permeability as previously described (1), volume changes were measured in the presence of the ionophore gramicidin to induce a high permeability to $\mathrm{Na}^{+}$and $\mathrm{K}^{+}$. As noted by Grinstein et al. (2), under these conditions, losses or gains of salts and associated changes in volume are limited by the conductive anion permeability of the cell membrane. The volume changes, therefore, provide a measure of anion permeability in general and of chloride permeability in particular. For the measurements, platelets were suspended in isotonic $\mathrm{NaCl}$ (Tyrode's modified medium) for $7.5 \mathrm{~min}$ utes in the presence of $0.4 \mu \mathrm{mol} / 1$ gramicidin. On dilution with water to $2 / 3$ of the original osmolarity, a very rapid, continuing swelling is observed, indicating chloride permeability. The rate constant of the permeability (relative volume change over time) was calculated as described (1). For the experiments designed to study the effect of divalent cations (figs. 2, 3 and 4) platelets were suspended in isotonic medium containing a mixture of $\mathrm{NaCl}$ and $\mathrm{KCl}$ Tyrode solutions $(2+1$, by vol $)$ and the suspension was diluted with water as above. In figures 2 and 4 , at the time points indicated, individual aliquots were separated and treated with 0.4 $\mu \mathrm{mol} / \mathrm{l}$ gramicidin. The relative volume changes were measured by electronic sizing. 


\section{Other measurements}

Cyclic AMP level in platelets was measured by a protein binding assay according to Gilman (10).

Platelet aggregation was assayed as previously described (11).

The final free $\mathrm{Ca}^{2+}$ concentrations and the concentration of the various divalent cations to be added to achieve a final free concentration of $0.15 \mu \mathrm{mol} / \mathrm{l}$ in the presence of $2 \mathrm{mmol} / \mathrm{l}$ EGTA were calculated by the software "Chelation 2", developed by Prof. $D$. Chipman from Beer Sheva, according to the dissociation constants of each of the cations with EGTA.

\section{Results}

In a previous paper (1), conditions were established for the evaluation of the conductive anion permeability in platelets. It is based on platelets suspended in isotonic $\mathrm{NaCl}$ medium in the presence of the ionophore gramicidin to induce a high permeability to cations. Upon induction of hypotonicity, gain of chloride is associated with volume increase, which is limited by the conductive chloride permeability. Thus, the extent of swelling under these conditions apparently provides a measurement of chloride permeability. Some characteristics of the platelet conductive anion transport were described (1).

If the system described indeed reflects conductive chloride permeability, then it is conceivable that an inhibitor of chloride channels - 5-nitro-2-(3-phenylpropylamino) benzoic acid - would inhibit the activity measured comparable to results in other cell types $(12,13)$. Figure 1 depicts the inhibitory profile of 5-nitro-2-(3-phenyl-

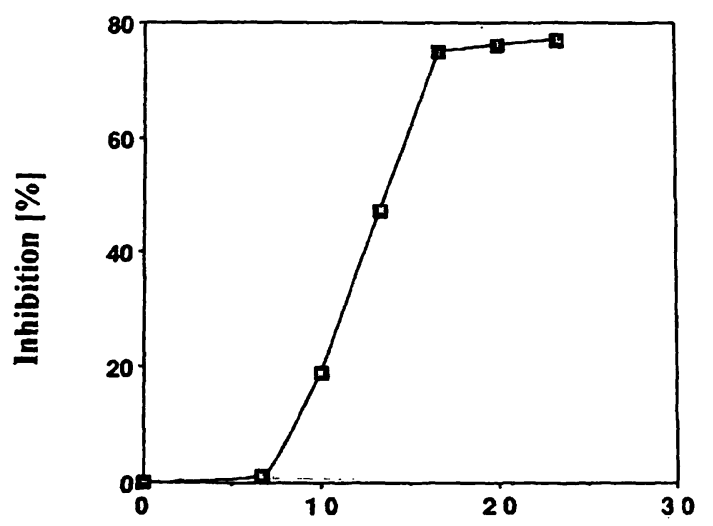

5-Nitro-2-(3-phenylpropylamino) benzoic acid $(\mu \mathrm{mol} / /)$

Fig. 1 Inhibition of the volume-induced chloride permeability by 5-nitro-2-(3-phenylpropylamino) benzoic acid.

Platelets $\left(2 \times 10^{6}\right)$ were suspended in $10 \mathrm{ml}$ of isotonic Tyrode medium (modified) in which $\mathrm{Cl}^{-}$is the predominant anion, supplemented with $0.4 \mu \mathrm{mol} / 1$ gramicidin. After 7.5 minutes the suspension was diluted with $5 \mathrm{ml}$ of water to $200 \mathrm{mosmol} / \mathrm{l}$ and the relative volume changes were measured by electronic sizing (a representative $\mathrm{Cl}^{-}$permeability sequence is depicted in fig. 5). 5-Nitro2-(3-phenylpropylamino) benoic acid at the indicated concentrations was added 1 minute before the addition of the water. propylamino) benzoic acid upon platelet chloride permeability. The inhibition is detected at concentrations above $5 \mu \mathrm{mol} / \mathrm{l}$ and reaches a plateau of $80 \%$ inhibition above $20 \mu \mathrm{mol} / \mathrm{l}$. Further characterization of the system is now provided.

\section{The involvement of divalent cations}

In the previous study (1), it was shown that platelets, suspended in an isotonic medium containing $\mathrm{NaCl}$ and $\mathrm{KCl}$ in a ratio of $2: 1$, upon induction of hypotonicity, react by initial osmotic swelling and do not change their volume for over one hour. Moreover, the maximal rates of the secondary swelling, initiated by gramicidin added at various times after the initial swelling, are remarkably similar. Figure 2 shows the involvement of $\mathrm{Ca}^{2+}$ in this gramicidin-induced swelling. When $2 \mathrm{mmol} / \mathrm{l}$ EGTA are added to the platelet suspension, the half-life of the decline of the chloride permeability is $30 \pm 3$ minutes (mean of 11 experiments $\pm \mathrm{SE}$ ). However, the addition of equimolar concentrations of both EGTA and $\mathrm{Ca}^{2+}$ $(2 \mathrm{mmol} / \mathrm{l})$ extends the capability of the process for at least 50 minutes. Figure 3 depicts the dependence of the permeability upon $\mathrm{Ca}^{2+}$ concentration. The concentration necessary to maintain half maximal activity $\left(c_{1 / 2}\right)$ after 30 minutes in the hypotonic medium is 0.14 $\mu \mathrm{mol} / \mathrm{l}$. Is the effect of $\mathrm{Ca}^{2+}$ specific? This issue was addressed by the comparison of the effect of seven divalent cations of two different metal families: $\mathrm{Mg}, \mathrm{Ca}, \mathrm{Sr}$ and $\mathrm{Ba}$ of the earth alkali metals and $\mathrm{Mn}, \mathrm{Cd}$ and $\mathrm{Cu}$ of the transition metals group. In the presence of EGTA

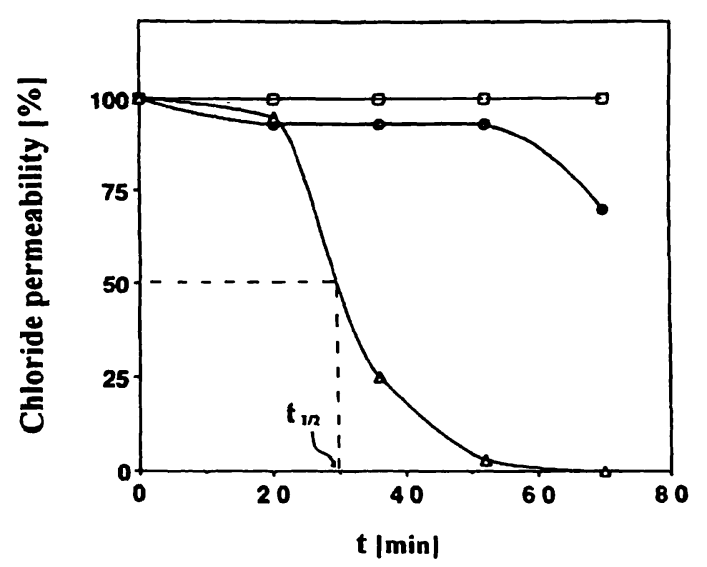

Fig. 2 Effect of EGTA and $\mathrm{Ca}^{2+}$ on the extent of chloride permeability with time.

Experimental conditions as in figure 1.

Gramicidin was omitted from the Tyrode medium. In parallel experiments, the medium was supplemented by either $1 \mathrm{mmol} / \mathrm{Ca}^{2+}$ to serve as the control $(\square), 2 \mathrm{mmol} / 1$ EGTA $(\triangle)$ or $2 \mathrm{mmol} / / \mathrm{EGTA}$ and $2 \mathrm{mmol} / / \mathrm{Ca}^{2+}(\odot)$. Gramicidin was added to the controls and the tests at various time intervals after the induction of hypotonicity (zero time), and chloride permeability, measured by cell swelling, followed. The rate constants obtained with EGTA only or EGTA and $\mathrm{Ca}^{2+}$ at each time interval were compared with the corresponding control designated as $100 \%$. 


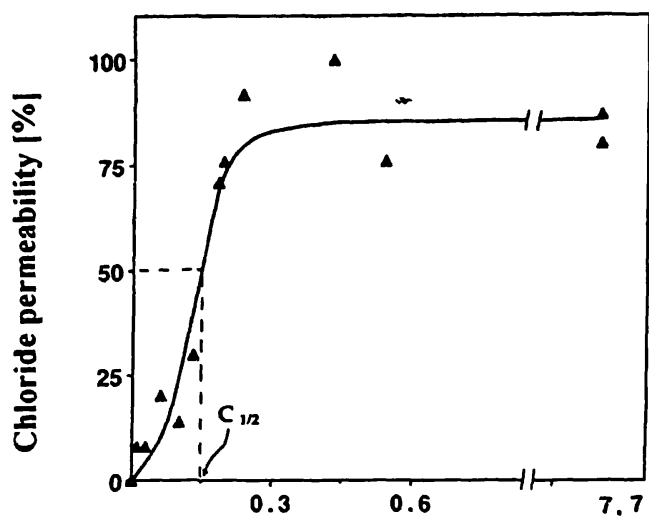

Extracellular free ionized $\mathrm{Ca}^{2}+[\mu \mathrm{mol} /]$

Fig. 3 The effect of extracellular free $\mathrm{Ca}^{2+}$ concentration on the extent of chloride permeability.

The experimental design was as described in figure 2. EGTA and $\mathrm{Ca}^{2+}$ were added to the Tyrode medium to gain the final free $\mathrm{Ca}^{2+}$ concentrations as indicated. These were calculated by the software "Chelaton 2" (Methods). Gramicidin was added 30 minutes after the induction of hypotonicity.

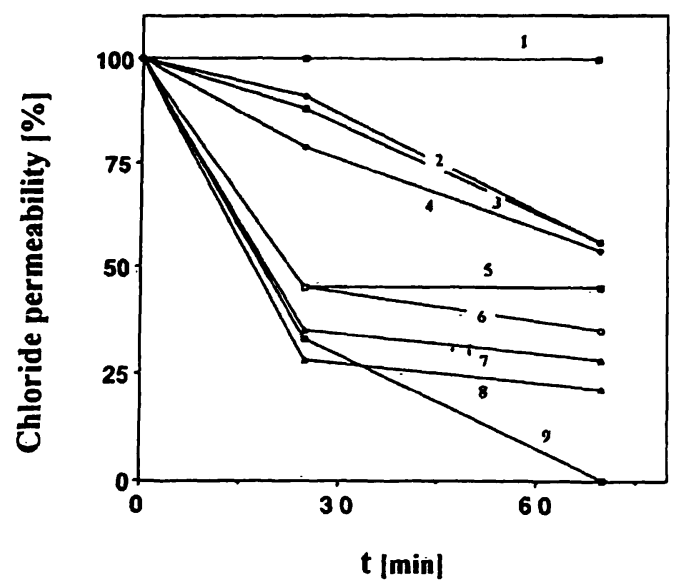

Fig. 4 The effect of divalent cations on the extent of chloride permeability with time.

Experimental conditions as in figure 3 with $2 \mathrm{mmol} / \mathrm{l} \mathrm{EGTA}$ and appropriate concentrations of the cations to produce final free concentrations of $0.15 \mu \mathrm{mol} / 1$ each. The calculation of the concentrations to be added was carried out with the software "Chelation 2" (Methods).
1. control $\left(1 \mathrm{mmol} / \mathrm{Caa}^{2+}\right)$
2. $\mathrm{Cd}^{2+}$
3. $\mathrm{Cu}^{2+}$
4. $\mathrm{Ca}^{2+}$
5. $\mathrm{Mn}^{2+}$
6. $\mathrm{Ba}^{2+}$
7. $\mathrm{Mg}^{2+}$
8. $\mathrm{Sr}^{2+}$
9. $2 \mathrm{mmol} / 1 \mathrm{EGTA}$

and at a final equal concentration of the free cation of $0.15 \mu \mathrm{mol} / 1, \mathrm{Ca}^{2+}, \mathrm{Cd}^{2+}$ and $\mathrm{Cu}^{2+}$ apparently show the same "protective" effect while the other four fail to fulfill the need for the cation (fig. 4). This, of course, may result from different (lower) affinities for $\mathrm{Mn}^{2+}, \mathrm{Ba}^{2+}$, $\mathrm{Mg}^{2+}$ and $\mathrm{Sr}^{2+}$.

\section{The impact of cyclic AMP}

Since chloride channels in several cells are known to be regulated by cyclic AMP levels (14-16), and since prostaglandin $E_{1}$ is known to elevate cyclic AMP concentrations (17), the effect of prostaglandin $E_{1}$ on platelet swelling limited by chloride permeability was studied. Figure 5 depicts an accelerated chloride permeability in the presence of $0.1 \mu \mathrm{mol} / 1$ prostaglandin $E_{1}$. Table 1 summarizes the results of ten similar experiments showing a statistically significant $44 \%$ enhancement of the apparent platelet chloride permeability caused by prostaglandin $E_{1}$. Is the effect of prostaglan$\operatorname{din} \mathrm{E}_{1}$ mediated by cyclic AMP? Two lines of evidence suggest a positive answer. First, table 2 demonstrates that under the conditions of the experiments described in figure 5 and table 1, cyclic AMP concentration is indeed elevated six fold by prostaglandin $E_{1}$. Secondly, ADP-induced platelet aggregation, known to be inhibited by elevated cyclic AMP concentrations, was totally abolished by as little as $0.02 \mu \mathrm{mol} / \mathrm{l}$ prostaglandin $E_{1}$ (data not shown).

Of particular interest is whether the system described has any relevance to the expression of cystic fibrosis. In view of the fact that it has been shown that the defect in cystic fibrosis patients is not the activity of the chloride channel but rather its response to control mechanisms such as an increase by cyclic AMP-dependent protein kinase $(15,18)$, the response of platelet chloride transport to prostaglandin $E_{1}$ in cystic fibrosis patients was evaluated (tab. 3). Nine patients were probed. Their rate constants of chloride permeability did not differ from those of healthy volunteers. However, five of them did not respond to prostaglandin $\mathrm{E}_{1}$ (as compared to a minimum response of $15 \%$ augmentation in all the control

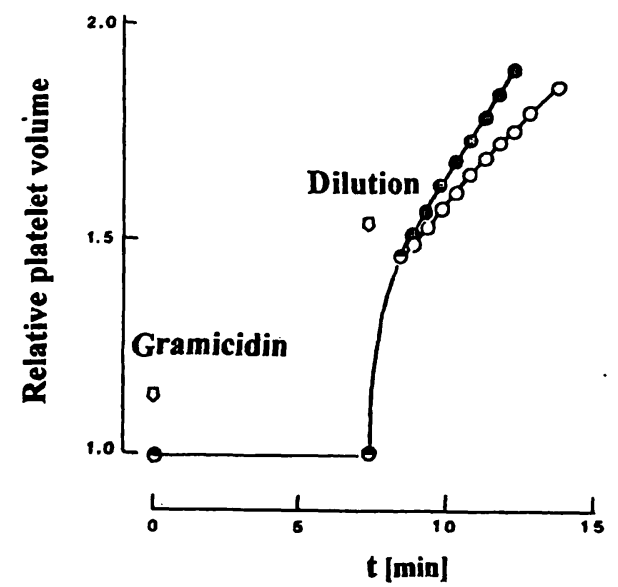

Fig. 5 Effect of prostaglandin $E_{1}$ on chloride permeability in control platelets. Experimental conditions - as described for figure 1. Prostaglandin $E_{1} \quad 0.1 \mu \mathrm{mol} / \mathrm{l}$ (solid circles) or its solvent $-1 \mathrm{ml}$ ethanol (open circles) were added at the time of dilution. Representative of ten experiments.

Temperature was $25^{\circ} \mathrm{C}$. 
subjects studied, summarized in tab. 1), but four did respond normally to the prostaglandin.

Tab. 1 Enhanced volume-induced chloride permeability by prostaglandin $\mathrm{E}_{1}$

\begin{tabular}{ll}
\hline Treatment & $\begin{array}{l}\text { Rate constant } \\
\min ^{-1}\end{array}$ \\
\hline Control & $0.109 \pm 0.008$ \\
Prostaglandin $\mathrm{E}_{1}, 0.1 \mu \mathrm{mol} / 1$ & $0.157 \pm 0.011$ \\
\hline
\end{tabular}

The experimental conditions were as in figures 1 and 5 .

Results are means of ten experiments \pm S.E.

The stimulatory effect of prostaglandin $E_{1}$ is statistically significant according to the Student's t test, $\mathrm{p}<0.01$. Neither of the individuals studied responded by less than $15 \%$ augmentation.

Tab. 2 Effect of prostaglandin $E_{1}$ on platelet cyclic AMP concentration

\begin{tabular}{lc}
\hline Treatment & cAMP \\
& pmol/109 platelets \\
\hline Control & 2.8 \\
Prostaglandin $\mathrm{E}_{1}, 0.1 \mu \mathrm{mol} / 1$ & 17.0 \\
\hline
\end{tabular}

Platelet-rich plasma was incubated with either ethanol $(1 \mathrm{ml} / \mathrm{l})$ or prostaglandin $E_{1}(0.1 \mu \mathrm{mol} / \mathrm{l})$ for one minute, followed by centrifugation and aspiration of the supernatant.

Cyclic AMP in the pellet was extracted by boiling for $5 \mathrm{~min}$ in 50 $\mathrm{mmol} / /$ acetate buffer $\mathrm{pH}$ 4.0.

The results are means of duplicates.

Tab. 3 Response of volume-induced chloride permeability of cystic fibrosis patients to prostaglandin $E_{1}$

\begin{tabular}{lllll}
\hline Patient & Sex & $\begin{array}{l}\text { Age } \\
\text { (a) }\end{array}$ & $\begin{array}{l}\text { Genotype } \\
\text { paternal/maternal }\end{array}$ & $\begin{array}{l}\text { Response to } \\
\text { prostaglandin } \\
\mathrm{E}_{1}{ }^{*} \text {, } \\
\text { ratio of the } \\
\text { rate constants }\end{array}$ \\
\hline M.M. & $\delta$ & $2.5 / 12$ & G542X/G542X & 1.63 \\
A.Y. & $\delta$ & 2 & N.A.** & 1.55 \\
M.Y. & $\delta$ & 2 & DF508/? & 2.00 \\
E.R. & $\$$ & 3 & N.A.** & 1.35 \\
F.E. & $\delta$ & 9 & DF508/W1282X & 1.00 \\
P.A. & $\delta$ & 9 & W1282X/DF508 & 1.00 \\
S.S. & $\delta$ & 13 & $3849+10 k b C \rightarrow T$ & 1.00 \\
S.Y. & $\delta$ & 14 & $3849+10 k b C \rightarrow T$ & 1.00 \\
H.B. & $\delta$ & 17 & DF508/DF508 & 1.00 \\
\hline
\end{tabular}

The experimental conditions are as in figure 1.

Each patient was assayed versus an age- and sex-matched healthy volunteer.

At least four assays were carried out from a given patient's blood sample.

Two of the patients were assayed under two different occasions with the same results.

* The values express the stimulation of the rate constant caused by $0.1 \mu \mathrm{mol} / \mathrm{l}$ prostaglandin $\mathrm{E}_{1}$ as compared with the vehicle (aqueous ethanol, volume fraction 0.7 )

** Not available.

\section{Discussion}

Conductive platelet anion permeability, mainly chloride permeability, is relatively low in isotonic medium and increases substantially on hypotonic swelling (1). This fact was used in the present work to study the control of this conductive feature in healthy people as well as in cystic fibrosis patients. To further support the interpretation that the assay previously developed (1) does indeed measure chloride transport, inhibition by a chloride channel blocker, 5-nitro-2-(3-phenylpropylamino) benzoic acid $(12,13)$, is documented, which adds to the previously observed inhibition by oligomycin C (1), shown to inhibit chloride pathways in lymphocytes (19). However, the results of Haws et al. (20) of "little or no inhibition" of cystic fibrosis transmembrane conductance regulator channels in immortalized human airway cells by $100 \mu \mathrm{mol} / 1$ 5-nitro-2-(3-phenylpropylamino) benzoic acid prevent us from drawing an unequivocal conclusion.

The dependence of the chloride permeability upon specific divalent cations indicates that there are at least two factors which affect chloride transport in platelets; one is catabolic - associated with cyclic AMP, and the other is concerned with cations. Another possibility, as shown for epithelial cells $(21,22)$ and epithelial apical membrane (23), is that $\mathrm{Ca}^{2+}$ and cyclic AMP activate different chloride channels (23). Other options - such as the change in $\mathrm{Ca}^{2+}$ concentrations resulting in altered cytoskeleton and subsequent swelling - are still open.

Apical chloride channels are opened and chloride secretion is stimulated by a variety of hormones and neurotransmitters that increase intracellular levels of cyclic AMP $(24,25)$. The same regulatory pattern is now principally demonstrated in platelets. Prostaglandin $E_{1}$ enhances cell swelling limited by chloride permeability, an effect that correlates with the elevation of cyclic AMP levels and with the inhibition of platelet aggregation well known to occur upon increased cyclic AMP concentration (17). Nevertheless, it cannot be ruled out that cyclic AMP alters platelet cytoskeleton, changes intracellular $\mathrm{Ca}^{2+}$ concentrations or activates transporters, resulting in a relative volume change.

In cystic fibrosis patients, the main molecular defect has been identified as chloride impermeability in various epithelia (26-30). In fact, hormonal secretagogues do stimulate cyclic AMP accumulation appropriately, but the chloride channels fail to open $(26,31)$. To study the pathophysiology of the disease at the biochemicalphysiological regulatory level in platelets, the effect of prostaglandin $\mathrm{E}_{1}$ on platelet chloride conductive permeability in cystic fibrosis patients was probed. The well known heterogeneity in the clinical presentation of cys- 
tic fibrosis, such as the involvement or absence of pancreatic insufficiency (32), and the variation in the severity of the disease in the whole community (33) have been partially attributed to different mutations at the cystic fibrosis locus. Studies of the correlation of cystic fibrosis mutations with pancreatic function, meconium ileus, liver involvement, lung disease and gender have been reported and reviewed $(34,35)$. Relevant examples are:

(a) remarkable correlation between $\Delta \mathrm{F} 508$ homozygosity $(\Delta \mathrm{F} 508 / \Delta \mathrm{F} 508)$ and pancreatic insufficiency ("severe" mutation) versus a genotype of $\Delta F 508 /$ non- $\Delta F 508$ or non- $\Delta \mathrm{F} 508 /$ non- $\Delta \mathrm{F} 508$ that have a mutant cystic fibrosis product that confers a sufficient phenotype (36);

(b) a severe disease, reflected by pancreatic insufficiency, high incidence of meconium ileus, early age at diagnosis, poor nutritional status and variable pulmonary function, is associated with homozygosity for the W1282X mutation and the heterozygosity for the $\Delta \mathrm{F} 508$ and W1282X mutations (9). The variability is intriguingly reflected in the patients studied by us as well. Of the nine tested, five patients lacked the regulatory response to prostaglandin $E_{1}$ stimulation, whereas the other four were responsive. Although the number of patients is limited, it is notable that in agreement with the examples described above, neither of the four responding patients exhibits the "severe" mutations, while three out of the five non-responders possess the severe mutations (F.E., P.A. and H. B.) while the other two carry the rare mutation $3849+10 \mathrm{kbC} \rightarrow \mathrm{T}$ which is not yet well characterized. Along with the fact that the chloride channel response to cyclic AMP-dependent protein kinase is defected in cystic fibrosis patients rather than the activity itself, there is good evidence that some mutant cystic fibrosis transmembrane conductance regulators are defectively processed (37) and that the very activity

\section{References}

1. Livne A, Grinstein S, Rothstein A. Volume-regulating behaviour of human platelets. J Cell Physiol 1987; 131:354-63.

2. Grinstein S, Clarke CA, Dupre A, Rothstein A. Volume-induced increase in anion permeability in human lymphocytes. $J$ Gen Physiol 1982; 80:801-23.

3. Halley DJ, Bijman J, De Jonge HR, Sinaasappel M, Neijens $\mathrm{HJ}$, Niermeijer MF et al. The cystic fibrosis defect approached from different angles - new perspectives on the gene, the chloride channel, diagnosis and therapy. Eur J Pediatr 1990; 149:670-7.

4. Frizzell RA, Cliff WH. Cystic fibrosis - back to the chloride channel. Nature 1991; 350:277-8.

5. Anderson MP, Gregory RJ, Thompson S, Souza DW, Paul S, Mulligan RC, et al. Demonstration that CFTR is a chloride channel by alteration of its anion selectivity. Science 1991; 253:202-5.

6. Higgins CF, Hyde SC. Cystic fibrosis - channelling our thoughts. Nature 1991; 352:194-5. of the chloride channel is altered (38). Such mutations have been implicated to be associated with the milddisease-form. Thus, it may also be suggested that the four responding patients in the present study belong to this group of mutations. It is interesting to point out that the non-responsive patients in the present study were all above nine years old, while the responsive ones were aged three years or less. Such a phehomenon could theoretically be understood if cystic fibrosis were an acquired disease but not a congenital one. Yet, the majority of the patients are diagnosed by the time of adolescence. This fact may suggest that although hereditary, some of the molecular manifestations of the disease are expressed at a later stage of life. It might be that at an early stage some of the components of the chloride transport complex are still capable of leaking adequately from the endosomal membranes to the functional sites in the plasma membrane. At later stages of life they may become arrested for numerous reasons, as yet unclear Such a possibility adds interest to the study of the system, but it does not allow the use of the assay of prostaglandin $E_{1}$ enhancement of platelet chloride conductive permeability as a reliable diagnostic tool for cystic fibrosis. It could, however, be used as a tool to follow the development of the disease. The main advantage of the platelet system is that it serves as an easily available, simple assay system to further study characteristics of the chloride transport system in health and disease.

\section{Acknowledgements}

The study was conducted at the Amelia (Mimi) Rose Signal Transduction Laboratory at the Department of Life Science. We thank Dr. Bill Brauer from Jerusalem, Mr. A. Margalit from Beer Sheva, and Prof. J. Funder from Copenhagen for constructive consultations. We are grateful to Ron and Annette Oelbaum from Toronto, Canada, for their aid. The technical assistance of Mrs. S. Veil in the assay of cyclic AMP is gratefully appreciated.
7. Kartner JW. Expression of the cystic fibrosis gene in non-epithelial invertebrate cells produces a regulated anion conductance. Cell 1991; 64:681-91.

8. Bear CE, Li C, Kartner N, Bridges RJ, Jensen TJ, Tamjeesingh $M$, et al. Purification and functional reconstitution of the cystic fibrosis transmembrane conductance regulator (CFTR). Cell 1992; 69:809-18.

9. Shoshani T, Augarten A, Gazit E, Bashan N, Yahav Y, Rivlin $\mathrm{Y}$, et al. Association of a nonsense mutation (W1282X), the most common mutation in the Ashkenazi Jewish cystic fibrosis patients in Israel, with presentation of severe disease. Am J Hum Genet 1992; 50:222-8.

10. Gilman AG. A protein binding assay for adenosine 3,5'-cyclic monophosphate. Proc Natl Acad Sci USA 1970; 67:305-12.

11. Agam G, Livne A. Resolution and reconstitution of interplatelet recognition during aggregation. Thromb Haemostas 1988; 59:504-6. 
12. Rugolo M, Mastocola T, Glamigni A, Lenaz G. Chloride transport in human fibroblasts is activated by hypotonic shock. Biochem Biophys Res Commun 1989; 160:1330-8.

13. Gray MA, Plant S, Argent BE. cAMP-regulated whole cell chloride currents in pancreatic duct cells. Am J Physiol [Cell Physiol] 1993; 33:C591-C602.

14. Knowles MR, Gatzy JT, Boucher RC. Relative ion permeability of normal and cystic fibrosis nasal epithelium. J Clin Invest 1983; 71:1410-7.

15. Schoumacher RA, Shoemaker RL, Halm DR, Tallant EA, Wallace RW, Frizzell RA. Phosphorylation fails to activate chloride channels from cystic fibrosis airway cells. Nature 1987; 330:752-4.

16. Frizzell RA, Rechkemmer G, Shoemaker RL. Altered regulation of airway epithelial cell chloride channels in cystic fibrosis. Science 1986; 233:558-60.

17. Pareti FI, Capitanio A. In: de Gaetano G, Garattini S, editors. Platelet biochemistry and metabolism in platelets: a multidisciplinary approach. New York: Raven Press, 1978:35-44.

18. Li M, McCann JD, Liedtke CM, Nairn AC, Greengard P. Cyclic AMP-dependent protein kinase opens chloride channels in normal but not cystic fibrosis airway epithelium. Nature 1988; 331:358-60.

19. Sarkadi B, Cheung R, Mack E, Grinstein S, Gelfand EW, Rothstein A. Cation and anion transport pathways in volume regulatory response in human lymphocytes to hypo-osmotic media. Am J Physiol 1985; 248:C480-C487.

20. Haws C, Krouse ME, Xia Y. CFTR channels in immortalized human airway cells. Am J Physiol [Lung Cell Mol Physiol] 1992; 7:L692-L707.

21. Cliff WH, Frizzell RA. Separate $\mathrm{Cl}^{-}$conductance activated by cAMP and $\mathrm{Ca}^{2+}$ in $\mathrm{Cl}^{-}$-secreting epithelial cells. Proc Natl Acad Sci USA 1990; 87:4956-60.

22. Vaandrager $A B, B$ ajnath $R$, Groot JA, Bot $A G M$, de Jonge HR. $\mathrm{Ca}^{2+}$ and CAMP activate different chloride efflux pathways in HT-29, cl. 19A colonic epithelial cell line. Am J Physiol [Gastrointes Liver Physiol] 1991; 24:G959-G965.

23. Anderson MP, Welsh MJ. Calcium and cAMP activate different chloride channels in the apical membrane of normal and cystic fibrosis epithelia. Proc Natl Acad Sci USA 1991; 88:6003-7.

24. Welsh MJ. An apical-membrane chloride channel in human tracheal epithelium. Science 1986; 232:1684-50.

25. Welsh MJ. Electrolyte transport by airway epithelia. Physiol Rev 1987; 67:1143-84.
26. Quinton PM. Chloride impermeability in cystic fibrosis. Nature 1983; 301:421-2.

27. Widdicombe $\mathrm{JH}$, Welsh MJ, Finkbeiner WE. Cystic fibrosis decreases the apical membrane chloride permeability of monolayers cultured from cells of tracheal epithelium. Proc Natl Acad Sci USA 1985; 82:6167-71.

28. Knowles MR, Stutts MJ, Spock A, Fischer N, Gatzy JT, Boucher RC. Abnormal ion permeability through cystic fibrosis respiratory epithelium. Science 1983; 221:1067-70.

29. Sato K, Sato F. Defective beta adrenergic response of cystic fibrosis sweat glands in vivo and in vitro. J Clin Invest 1984; 73:1763-71.

30. Kopelman H, Durie P, Gaskin K, Weizman Z, Forstner G. Pancreatic fluid secretion and protein hyperconcentration in cystic fibrosis. N Engl J Med 1985; 312:329-34.

31. Welsh MJ, Liedtke CM. Chloride and potassium channels in cystic fibrosis airway epithelia. Nature 1986; 322:467-70.

32. Gaskin K, Gurwitz D, Durie P, Corey M, Levison H, Forstner G. Improved respiratory prognosis in patients with cystic fibrosis with normal absorption. J Pediatr 1982; 100:857-62.

33. Rosenstein BJ, Langbaum TS, Winn K. Unexpected diagnosis of cystic fibrosis at autopsy. South Med J 1984; 77:1383-5.

34. Ferrari M, Antonelli M, Bellini F, Borgo G, Castiglione D, Curcio L, et al. Genetic differences in cystic fibrosis patients with and without pancreatic insufficiency. An Italian collaborative study. Hum Genet 1990; 84:435-8.

35. Tizzano EF, Buchwald M. Cystic fibrosis: beyond the gene to therapy. J Pediat 1992; 120:337-49.

36. Kerem E, Corey M, Kerem B, Rommers J, Markiewicz D, Levison $\mathrm{H}$, et al. The relation between genotype and phenotype in cystic fibrosis: analysis of the most common mutation ( $\triangle$ F508). N Engl J Med 1990; 323:1517-22.

37. Cheng SH, Gregory RJ, Marshall J. Defective intracellular transport and processing of CFTR is the molecular basis of most cystic fibrosis. Cell 1990; 63:827-34.

38. Sheppard, DN, Rich DP, Ostedgaard LS. Mutations in CFTR associated with mild-disease-form $\mathrm{Cl}^{-}$channels with altered pore properties. Nature 1992; 362:160-4.

Galila Agam, Ph. D., Director

Laboratory of Biochemistry

Soroka Medical Center

P.O. B. 151

Beer Sheva 84101

Israel 


$$
\text { • }
$$

